Encontro Nacional de

Economia Industrial e Inovação
Indústria e Desenvolvimento Econômico:

desafios e perspectivas

18 a 20 de setembro de 2018

Uberlândia - Minas Gerais

\title{
Mudança Estrutural e a Produtividade: análise da economia brasileira
}

Prof $^{\mathrm{a}}$. Dr ${ }^{\mathrm{a}}$. Carolina Silvestri Cândido Rocha ${ }^{1}$

Prof $^{\text {a }}$. Dra ${ }^{\mathrm{a}}$. Ana Lúcia Tatsch ${ }^{2}$

Prof. Dr. Silvio Antonio Ferraz Cario ${ }^{3}$

Observa-se na realidade de diversos países, desenvolvidos e em desenvolvimento, a ocorrência de mudança estrutural em direção à redução da participação da indústria no PIB. Tal processo, denominado processo de desindustrialização, impacta a produtividade das economias de maneira diferente. Quando o setor de serviços emergente é capaz de ampliar a complexidade econômica, vê-se tendência de aumento de produtividade, no entanto, quando este não se relaciona diretamente ao setor industrial remanescente, ou seja, é composto por serviços não estratégicos, observa-se problemas no crescimento da produtividade. Neste contexto, por meio da utilização de um modelo de decomposição canônica de variância, a realidade brasileira foi analisada visando caracterizar a direção da mudança estrutural e compreender sua consequência tem termos de produtividade. Como resultado, verifica-se que o crescimento da participação do setor de serviços no emprego relaciona-se mais com um aumento do emprego nos segmentos de Serviços financeiros, seguros, imobiliário e comercial e Serviços comunitários, sociais e pessoais. Neste sentido, conclui-se que tal fenômeno decorre da ausência de dinamismo dos demais setores econômicos e não de medidas que proporcionam mudança estrutural para o aprofundamento da complexidade econômica e aumento da produtividade.

Palavras-chave: Mudança estrutural, produtividade, desindustrialização

Área ABEIN: 1.3 Crescimento, produtividade e competitividade

JEL: L50

In many developed and developing countries is possible to observe structural changing process, that means that the share of industry in GDP is decreasing. This process, called the deindustrialization process, impacts the productivity of economies differently. When the emerging services sector is able to increase the economic complexity, there is a tendency to increase productivity, however, when it is not directly related to the remaining industrial sector, that is, it is composed of non-strategic services, it is observed problems in productivity growth. In this context, through the use a canonical decomposition of variance's model, the Brazilian reality was analyzed aiming to characterize the direction of the structural change and to understand its consequence in terms of productivity. As a result, growth in the share of the services sector in employment is more related to an increase in employment in the financial, insurance, real estate and commercial services and community, social and personal services sectors. In this sense, it is concluded that this phenomenon stems from the implementation of policies focused on demand to the detriment of those that provide structural change to deepen economic complexity and increase productivity.

Keywords: Structural change, productivity, de-industrialization

\footnotetext{
${ }^{1}$ Universidade Estadual de Santa Catarina - UDESC

${ }^{2}$ Universidade Federal do Rio Grande do Sul - UFRGS

${ }^{3}$ Universidade Federal de Santa Catarina - UFSC
} 


\section{Introdução: mudança estrutural, inovação e produtividade}

Observa-se que diversas economias têm perpassado processos intensos de mudança estrutural, principalmente a partir da década de 1980. A indústria perde participação no PIB nas economias desenvolvidas, o que caracteriza um processo de desindustrialização. Nas economias emergentes tal fenômeno também pode ser observado. No entanto, em função destas economias não terem alcançado um nível elevado de industrialização e renda per capita faz deste processo um fenômeno precoce.

O presente artigo tem por objetivo analisar a relação entre mudança estrutural e produtividade na economia brasileira, visando ressaltar sua características e resultados por meio de uma variação do modelo de decomposição canônica apresentado por Fabricant (1942), apresentado em Timmer, De Vries e De Vries (2014). Assim como estes autores, McMillan e Rodrik (2011), Rodrik (2013), Timmer e Szirmai (2000) e Marconi e Aragão (2016) também apresentam estudos baseados no modelo de Fabricant (1942).

Este método permite mensurar a contribuição para a variação da produtividade da realocação de trabalhadores entre os distintos setores da economia. Neste contexto, o método permite isolar diferentes movimentos intra e extrasetoriais (a serem explanados adiante) e assim compreender como a realocação de trabalhadores entre setores da economia afeta a produtividade. Esta realocação representa um dos elementos que compõem a mudança estrutural.

A Cepal desenvolve-se como uma escola de pensamento especializada no exame de tendências econômicas e sociais. Seu vigor analítico, autônomo e normativo foi um dos estímulos decisivos para o desenvolvimento intelectual que presidiu a chamada "economia do desenvolvimento" como ramo das ciências econômicas. A sua importância para a análise do desenvolvimento dá-se em razão do esforço para diagnosticar a problemática de sistemas econômicos nacionais em fases distintas de desenvolvimento. Essa necessidade aproxima a economia de um estudo comparativo de problemas similares em variantes condicionadas por situações históricas diversas, e em distintos contextos nacionais, conhecido como análise econômica do método histórico (BIELSCHOWSKY, 2000; MACEDO, 2007; FURTADO, 1961).

Tal análise induziu o pensamento econômico a adotar um enfoque estrutural dos problemas, ao realizar a identificação do que é específico de cada estrutura, servindo de base para uma tipologia das estruturas. $\mathrm{O}$ estruturalismo original, criado em outras disciplinas das ciências sociais, caracteriza-se por um instrumental metodológico sincrônico ou a-histórico. Na análise econômica cepalina, o estruturalismo é essencialmente orientado pela busca de relações diacrônicas, históricas e comparativas (BIELSCHOWSKY, 2000; FURTADO, 1961).

O desenvolvimento econômico apresenta-se como resultado da introdução de fatores de produção que possibilitam aumento da produtividade do trabalho, seguindo um padrão de competitividade representado pela técnica moderna. $\mathrm{O}$ aumento da produtividade é alcançado através da incorporação dos frutos do progresso técnico ao trabalho, daí observa-se o papel determinante deste no desenvolvimento (FURTADO, 1961).

Neste sentido, o progresso técnico, tal como sua geração e difusão, figura como determinante primeiro da condição do desenvolvimento e da produtividade das economias mundiais ao longo da evolução do pensamento cepalino. A concepção acerca das estruturas que envolvem o progresso técnico também evolui com o pensamento da Cepal. Nos primeiros anos, a partir da criação da Cepal, o progresso técnico determina o desenvolvimento por meio das condições como seus frutos são gerados e difundidos, e a industrialização é a forma de propiciá-lo. A partir da década de 1980, um novo tratamento das questões pertinentes ao progresso técnico é proposto, e esta passa a se fazer necessário ao crescimento com equidade mediante a sua geração endógena.

A partir da década de 1980, a inovação e a difusão da tecnologia como processos endógenos aos mecanismos da competência econômica vem à tona definitivamente através das ideias de evolucionistas de Nelson e Winter (1982), e Fajnzylber (1983). O neoestruturalismo da década de 1990 pode ser considerado uma nova fase do pensamento cepalino com a conjunção entre o estruturalismo e a abordagem 
neoschumpeteriana. A tecnologia e a mudança estrutural voltam a ocupar lugar destacado, porém, o papel da tecnologia segue um caminho diferente do observado nas décadas anteriores.

Segundo Rodriguez (2006), o progresso técnico deixa de ser percebido como gerado fora do sistema econômico e incorporado, basicamente, aos bens de capital. Passa-se a entender que a consecução do progresso técnico depende das formas organizacionais que assumem as empresas. Desta maneira, deixa de ser visto como exógeno às atividades produtivas. Dadas as possibilidades de ser gerado internamente às empresas torna-o endógeno, chamado de "processo de inovação".

A relação entre inovação e mudança estrutural tem papel primordial no trabalho de Schumpeter. A inovação, como um processo de destruição criadora, é apresentada como fator determinante para a evolução das indústrias e elemento inerente ao processo de transformação econômica. Esta relaciona-se intimamente ao surgimento, crescimento e declínio das indústrias que marcaram historicamente o desenvolvimento do capitalismo. O desenvolvimento e transformação industriais associados ao surgimento e crescimento de diferentes setores derivam da concorrência entre as empresas, que introduzem novas tecnologias e produtos, conformando-se assim como operadores históricos que incidem sobre as tecnologias existentes. Tal processo descreve os nexos entre inovação e transformação industrial (MALERBA, 2006).

$\mathrm{Na}$ abordagem neoschumpeteriana, o princípio da análise concentra-se nas capacitações individuais e/ou empresariais, focando nas rotinas, decisões e processos de aprendizagem e inovação. É importante apontar que os protagonistas de tais processos agem sob incertezas e dispõem de racionalidade limitada. Assim, a produtividade deriva da inovação. As empresas mais produtivas são aquelas que condicionam suas rotinas em direção ao aumento de sua capacidade inovativa.

A análise das questões econômicas peculiares à estrutura produtiva assim como os condicionantes da geração e difusão do progresso técnico para superação do atraso e para a equidade, colocam o pensamento histórico-estruturalista cepalino e a abordagem neoschumpeteriana em consonância. A endogeneização do progresso técnico é o elo que relaciona as duas correntes de pensamento. Já familiarizado com o pensamento de Schumpeter, o estruturalismo passa a considerar o ideário neoschumpeteriano no neoestruturalismo, uma vez que os microfundamentos da inovação vêm à tona como condicionantes do desenvolvimento.

Assim, a análise do progresso técnico ganha profundidade: passa a relacionar o comportamento interno das firmas em seus processos de rotina, busca e seleção da inovação com a condição periférica das economias que deriva de sua baixa capacidade de gerar, assimilar e difundir o progresso técnico, assim como esta capacidade também é condicionada por sua condição periférica.

Em síntese, a produtividade conceituada nos termos da produtividade do trabalho, ou seja, na relação entre trabalhadores e produto, apresenta íntima relação com a mudança estrutural e com a inovação. A inovação enseja avanço no processo de capacitação empresarial o que, por sua vez, expressa-se nos sistemas econômicos por meio da mudança estrutural.

\section{Articulação indústria, serviços e a produtividade}

A relação entre as dinâmicas setoriais e a produtividade é amplamente abordada na literatura econômica. Os setores que compõem a economia apresentam características particulares que os distinguem. A indústria coloca-se como um setor particularmente capaz de elevar a produtividade das economias, uma vez que é intensivo em capital, o que permite que se amplie o valor agregado por trabalhador.

Neste contexto, o aumento recente da participação do setor de serviços nas economias fomentou o debate sobre como este fenômeno afetaria a evolução da produtividade. Segundo Jacinto e Ribeiro (2015), a produtividade da indústria passou a ser associada ao desempenho do setor de serviços, isso pois observase uma crescente participação deste no PIB.

A exemplo disto, Baumol (1967), Baumol et al (1985), Rodrik (2011, 2014), Busso et al (2013), Malo et al (1998), Castellacci (2007) estudam a relação entre o setor de serviços e a produtividade. Primeiramente, tinha-se a compreensão que o aumento da participação do setor de serviços no PIB promoveria uma estagnação na produtividade haja vista o parco desenvolvimento produtivo deste que era observado como um setor residual. Esta abordagem é conhecida como doença dos custos dos serviços. 
A observância do setor de serviços como residual e redutor da produtividade passa a ser contesta devido a dois aspectos. Primeiramente, pois o setor de serviços é altamente heterogêneo. Dentre deste observam-se segmentos que absorvem mão de obra de baixa qualificação e outros, como o segmento dos serviços de informação e software nos quais a inovação é permanente. E devido à forma como o setor de serviços altera-se no tempo. Este apresenta uma elevada capacidade de avançar frente às alterações nos ambientes competitivos. Como neste setor observa-se menor necessidade de imobilização de capital, muitas alterações paradigmáticas da economia o impactam rapidamente e promovem mudanças que depois estendem-se aos demais (SILVA, 2006; PEREIRA et al, 2013).

Nestes termos, pode-se separar, grosso modo, o setor de serviços em segmentos tradicionais, onde a inovação é menos presente e que são mais resistentes à mudança, mas que impactam o emprego e a geração de renda devido ao seu tamanho, e segmentos dinâmicos, onde a inovação é permanente e assim onde observa-se maior potencial de evolução e crescimento da produtividade (SILVA, 2006; PEREIRA et al, 2013).

No tocante à realidade brasileira, os estudos realizados acerca da produtividade e setor de serviços focam na relação deste com a indústria (JACINTO; RIBEIRO, 2015). Muitos buscam comprovar a existência da doença de custos na economia nacional. Melo et al (1998) aponta não encontrar evidencias que ratificam a ocorrência deste fenômeno para as décadas de 1980 e 1990. Oliveira (2011) aponta haver evidências que sinalizam que o setor de serviços contribuiu para o crescimento da produtividade agregada após 1994 e que, assim sendo, não se constata ocorrência de doença de custos no brasil até meados dos anos 2000.

No que se refere à realidade do setor de serviços no Brasil, vê-se que os serviços empresariais intensivos em conhecimento corroboram para a inovação, que há ineficiência no processo seletivo de empresas, uma vez que nem sempre as empresas menos produtivas são as que deixam o mercado, que existe concentração espacial importante no setor de serviços e que as empresas de capital estrangeiro são, em geral, mais produtivas que as de capital nacional. Da mesma forma que na indústria, variáveis relacionadas à escala, tecnologia, dotação de fatores contribuem para diferenciar empresas exportadoras e nãoexportadoras (SILVA; DE NEGRI; KUBOTA, 2006).

Observa-se que a produtividade do setor de serviços brasileiro é baixa, oscilante e heterogênea. O nível reduzido sugere que o setor opera com baixo nível de capital, tecnologia e que desenvolve pouca inovação. As oscilações podem decorrer de alterações nos preços relativos dos serviços e também de dificuldades e erros de medida. A heterogeneidade deriva desta característica própria do setor. Diferente de outros setores, as empresas menores tendem a ser mais produtivas, o que pode estar associada a fatores institucionais e à natureza menos favorável a ganhos de escala deste setor. Os indicadores associados ao capital humano e à integração econômica internacional estão entre as variáveis que mais condicionam a produtividade em serviços (ARBACHE, 2015).

A elevada participação do setor de serviços na economia nacional assim como sua elevada presença na matriz de custos de outras atividades econômicas ratifica a importância que o aumento da produtividade dos serviços tem para a economia nacional como um todo. A visão tradicional de que o setor de serviços apresenta baixos índices de produtividade e inovação per si é inadequada. O setor de serviços é extremamente heterogêneo e assim há segmentos mais dinâmicos que outros. Os serviços são insumos fundamentais para qualquer economia moderna e têm papel importante na difusão de inovações e de ganhos de produtividade para outros setores. Assim, frente às características econômicas atuais, o desenvolvimento passa pela consideração do setor de serviços como peça-chave para a produtividade (ARBACHE, 2015; SILVA; DE NEGRI; KUBOTA, 2006).

\section{Mudança estrutural e produtividade: cenário mundial}

Pelas diversas formas analisadas - razão entre o Valor Adicionado (VA) e o número de trabalhadores, PIB por trabalhadores, Produtividade Total dos Fatores (PTF) -, a conclusão, antes os movimentos mundiais da produtividade, é a mesma. Isto é, a produtividade tem mostrado tímido crescimento; o que já pode ser observado até mesmo antes da crise financeira global. 
A produtividade mundial acompanhou o baixo crescimento registrado no PIB em anos recentes. O crescimento da produtividade mundial, de 2013 a 2014, foi de apenas $2,1 \%$, insuficiente para recuperar o valor registrado em momento anterior à crise, de 2,6\% em média ao ano (de 1999 a 2006). A estagnação na produtividade global é resultado de poucas mudanças nas taxas de crescimento do produto e do emprego e, nos anos recentes, 2016 e 2017, observa-se pequeno avanço - a produtividade do trabalho cresceu 1,4 e $2 \%$, respectivamente (THE CONFERENCE BOARD, 2017).

O insignificante avanço da produtividade decorre de diversos fatores: da redução no crescimento da produtividade dos Estados Unidos e do Japão, desaceleração no crescimento da produtividade chinesa, estagnação na produtividade latino-americana e redução no crescimento da produtividade russa. Apenas na Índia e na África Subsaariana houve registro de aumento das taxas de crescimento, insuficientes para compensar a fraca performance dos outros países (THE CONFERENCE BOARD, 2017).

A redução das taxas de crescimento das economias maduras é um fenômeno de longo prazo, que se inicia antes da crise financeira e econômica de 2008-2009. Desde 2005, as taxas de crescimento da produtividade decrescem nos Estados Unidos, quando as inovações proporcionadas pela utilização das Tecnologias de Informação e Comunicação (TICs) foram absorvidas. Na Europa e no Japão, a tendência de crescimento da produtividade inferior àquela registrada nos Estados Unidos se inicia nos anos $1990 \mathrm{e}$ está relacionada a um ritmo mais vagaroso de adaptação e inovação tecnológica, especialmente no setor de serviços (THE CONFERENCE BOARD, 2017).

A relação entre a queda no crescimento da produtividade global e os movimentos de rápida mudança tecnológica e inovação, especialmente da fase recentes das TICs é contraditória. Historicamente, tais mudanças deveriam promover elevação na produtividade, assim, observa-se que a fraqueza no crescimento da produtividade nos últimos anos reflete a lentidão pela qual as novas tecnologias se traduziram em produtividade (DABLA-NORRIS et al., 2015; THE CONFERENCE BOARD, 2015).

A crise econômica e financeira global influencia isto, pois provocou redução na demanda, causando baixo investimento. A flexibilização monetária (quantitative easing) levou a retornos baixos nos investimentos da economia real. As baixas taxas de juros têm pouco efeito na aceleração do investimento. O baixo custo do capital pode ter deixado as empresas menos produtivas nos negócios e mudado os incentivos para que mantivessem caixa, bem como influenciou a alocação dos recursos dos investidores em instrumentos financeiros e imóveis, ao invés de investimentos produtivos que originassem oportunidades de crescimento e inovação (DABLA-NORRIS et al., 2015).

A queda no crescimento do capital humano e físico por trabalhador, desde a década de 1990, também contribui para o declínio da produtividade nas economias maduras ${ }^{4}$. O aprofundamento do capital das TICs, amplamente considerado como uma vantagem competitiva norte-americana na produtividade do trabalho sobre as economias europeias, recuou do pico alcançado em meados da década de 1990. O declínio no aprofundamento do capital não TIC em muitas economias avançadas também antecedeu a crise, refletindo em parte uma diminuição de longo prazo do investimento público. O nível de escolaridade também está próximo da estabilização na maioria das economias avançadas. Para as gerações nascidas depois de 1950, nos Estados Unidos, o aumento da escolaridade cessou (DABLA-NORRIS et al., 2015).

As economias em desenvolvimento ${ }^{5}$ registraram evolução no crescimento da produtividade do trabalho de 2014 (3,4\%), comparando-se à 2013 (3,3\%). O crescimento da produtividade dos mercados emergentes é inferior ao registrada no início dos anos 2000, quando a média figura entre 5 e $7 \%$. Nos anos recentes, 2016 e 2017, a produtividade cresceu 2,2 e 2,8\%, respectivamente. Porém, há diferença registrada entre as economias emergentes (THE CONFERENCE BOARD, 2017).

A produtividade chinesa registra taxas de crescimento decrescentes ao longo dos anos - de 2007 a 2012, a média foi de 9,5\%, em comparação a 7,3\% em 2013, e a 7\% em 2014. Na Índia, o crescimento da produtividade de 2,8\% em 2013 foi superado em 2014, quando atingiu 3,8\%, apesar da desaceleração em 2016, este país se destaca com uma das maiores taxas de crescimento da produtividade. Em contrapartida, a produtividade brasileira, que cresceu 1,8\% em 2013, registrou crescimento de apenas 0,3\% em $2014 \mathrm{e}$

\footnotetext{
${ }^{4}$ Estados Unidos, União Europeia, Japão, Austrália, Canadá, Islândia, Israel, Hong Kong, Noruega, Coréia do Sul, Suíça, Nova Zelândia, Singapura e Taiwan.

${ }^{5}$ Inclui as demais economias, exceto as Economias Maduras.
} 
decréscimo em 2015, 2016 e 2017. A produtividade mexicana apresentou pequeno aumento da taxa de crescimento, passando de 0,5\% em 2013 para 0,6\% em 2014, e a produtividade russa também reduziu seu crescimento: 0,4\% em 2014 em comparação a 1,5\% em 2013 (THE CONFERENCE BOARD, 2017).

A produtividade e a dinâmica setorial estão intimamente atreladas e as alterações setoriais recentes fornecem informações sobre o comportamento da produtividade. No tocante à mudança estrutural, a realocação de fatores produtivos entre setores pode promover elevação na produtividade quando ocorre em direção a setores de maior competitividade e eficiência.

Diferentes aspectos explicam esse processo nas economias avançadas e em desenvolvimento. Tome-se a globalização por exemplo, em muitas economias avançadas esse processo foi acompanhado pela terceirização de algumas atividades de alta produtividade para as economias emergentes. As mudanças tecnológicas, como a revolução das TICs e a mudança para produção mais intensiva em conhecimento, tiveram profundas implicações para as estruturas de produção.

Ao longo das últimas quatro décadas, as economias avançadas experimentaram mudanças em sua estrutura em benefício do setor de serviços, um processo de desindustrialização natural. As economias em desenvolvimento também apresentam tal tendência, mas de forma precoce, uma vez que não atingiram o mesmo padrão de renda per capita das economias avançadas (TIMMER; DE VRIES; DE VRIES, 2014).

No Gráfico 01, tem-se a participação da indústria e do setor de serviços no PIB dos países que compõem a $\mathrm{OCDE}^{6}$, da América Latina e do mundo. A participação referente ao setor de serviços corresponde ao eixo primário - à esquerda - e aquela referente ao setor industrial está localizada no eixo da direita. É possível observar que, além da participação média mais elevada do setor de serviços, este também apresenta tendência ascendente, ao passo que a indústria está em redução, o que ratifica o processo de desindustrialização tanto nas economias desenvolvidas quanto nas subdesenvolvidas.

Gráfico 01 - Participação da Indústria e Serviços no PIB dos países da OCDE, América Latina e mundo - 1997 a 2015 (em \%)

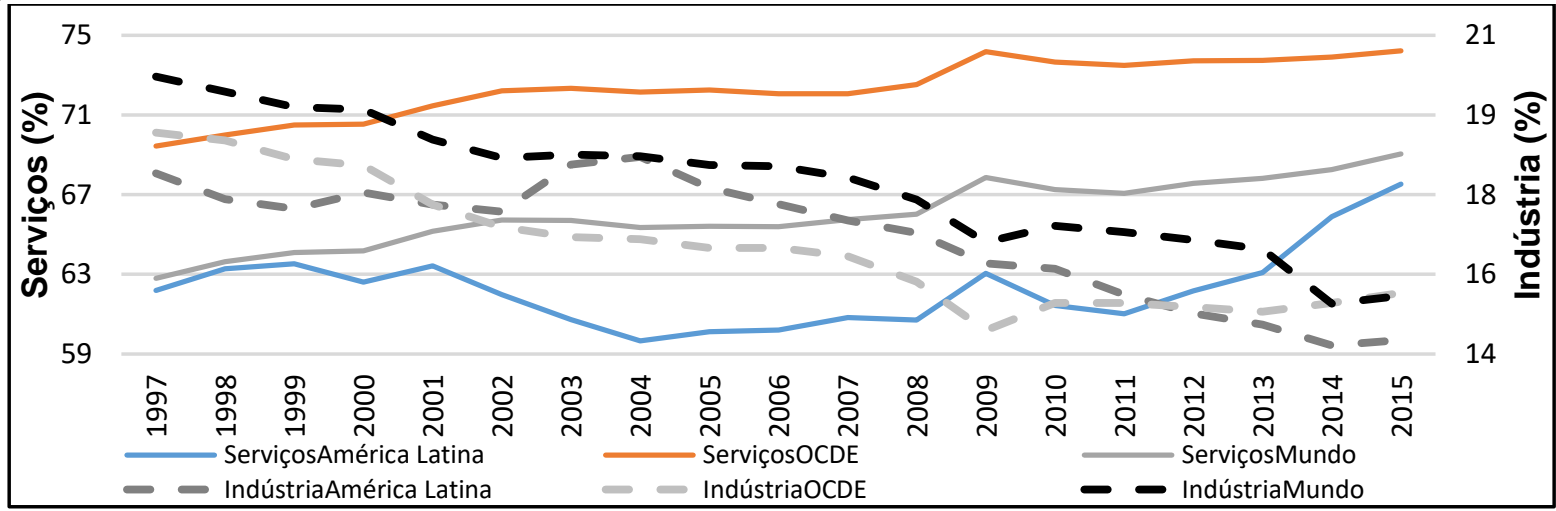

Fonte: Banco Mundial (2017).

Frente ao processo de desindustrialização observado nas economias, assim como a diferença deste em economias em fases distintas de desenvolvimento, o setor de serviços assim como seu comportamento simbiótico com a indústria tem se tornado tema relevante de análise. Neste contexto, a produtividade e a mudança estrutural dependem mais de alterações em direção ao aumento da complexidade das estruturas produtivas do que da participação da indústria nas economias.

Neste contexto, importa ressaltar que o setor de serviços capaz de promover aprofundamento da complexidade econômica surge após a consolidação de um setor industrial robusto. Completar o processo de industrialização é condição necessária para que o processo de desindustrialização, que ocorre naturalmente nas economias desenvolvidas, preserve a complexidade econômica.

Observa-se nas economias subdesenvolvidas que o processo precoce de desindustrialização faz emergir da estrutura econômica um setor de serviços de menor qualificação, incapaz de promover

\footnotetext{
${ }^{6}$ Irlanda, Estônia, Áustria, Austrália, Bélgica, Islândia, Polônia, Dinamarca, Alemanha, França, Finlândia, Coreia do Sul, Luxemburgo, Canadá, República Tcheca, Países Baixos, Estados Unidos, México, Noruega, Reino Unido, Chile, Portugal, Japão, Suécia, Suíça, Eslováquia, Eslovênia, Turquia, Espanha, Grécia, Nova Zelândia, Hungria, Israel, Itália e Letônia.
} 
aprofundamento da complexidade econômica. Pode-se afirmar que muito do crescimento observado no setor de serviços decorre de políticas econômicas de incentivo à demanda.

No que se refere aos serviços, este setor apresenta a peculiaridade de estar relacionado aos demais que compõem a estrutura produtiva dos países, e, entre eles, é o mais diversificado. Desse modo, uma economia com uma indústria robusta requer uma série de serviços de apoio - normalmente intensivos em conhecimentos, estratégicos, que proporcionam agregação de valor ao complexo industrial. Uma economia em que não se observa essa relação, no geral, sustentará serviços de baixas qualificação, complexidade e produtividade, voltados às famílias.

Quando abordam-se temas como regimes tecnológicos, trajetórias e produtividade em uma lógica intersetorial, a indústria apresenta papel preponderante, pois representa a engrenagem do crescimento e a parte mais inovadora dos sistemas econômicos. Porém, nos anos recentes, é possível verificar nesta dinâmica uma alteração que coloca o setor de serviços como parte importante do sistema, visto que tem experimentado rápido crescimento e é responsável pela maior parte do valor adicionado e do emprego nos países industrializados (CASTELLACCI, 2007).

No Gráfico 02, apresentam-se os dados referentes à produtividade do trabalho e à participação dos setorial para o ano de 2010. A produtividade setorial apresentada é relativa à produtividade total, o que permite desconsiderar as idiossincrasias nacionais. Os países selecionados visam permitir a comparação de realidades distintas de desenvolvimento e produtiva ${ }^{7}$. Em todos os países, a mineração destacou-se como o setor mais produtivo, o que decorre de sua intensidade em capital. Em seguida, o destaque é o setor industrial (indústria de transformação), que, exceto na China, apresenta-se como o segundo setor mais produtivo em todos os países. A importância da indústria como setor econômico é ratificada ao se observar a participação de cada setor no emprego total dos países selecionados. A indústria de transformação é, na maioria das economias (exceto na China), o setor que apresenta a segunda maior parcela de emprego, atrás apenas do setor de serviços. Combinando sua elevada participação no emprego (em torno de $20 \%$ ) com as suas características em termos de produtividade, tem-se a importância deste setor na estrutura produtiva.

Gráfico 02 - Produtividade setorial de países selecionados (VA a US\$ constantes de 2010/emprego - produtividade total do país $=\mathbf{1 0 0})-\mathbf{2 0 1 0}$

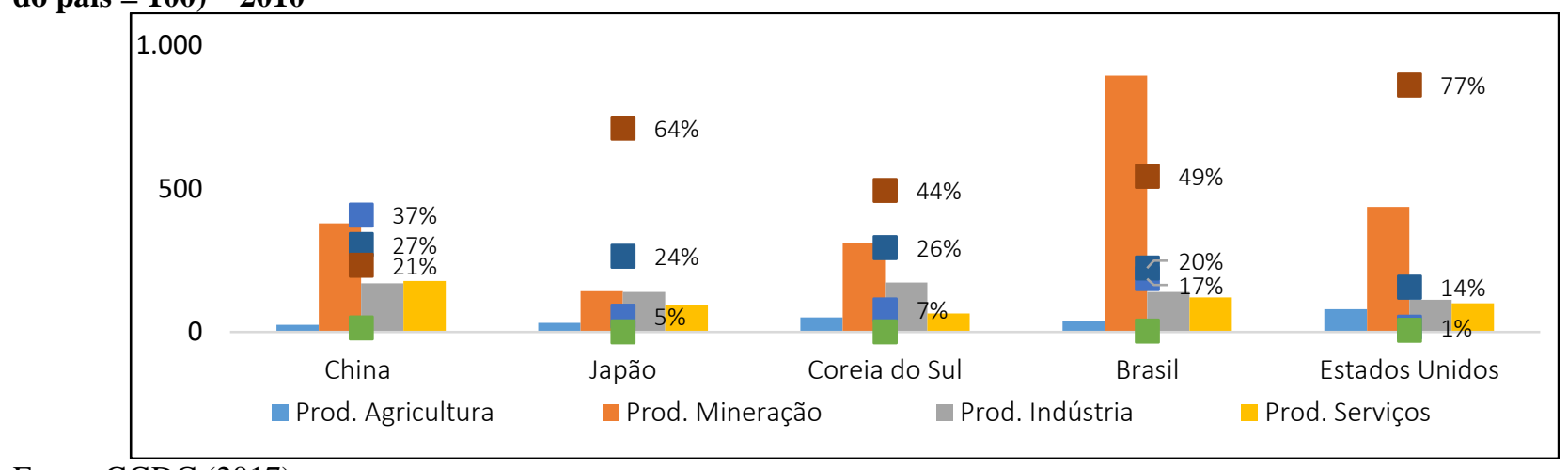

Fonte: GGDC (2017).

Tradicionalmente, explica-se a emergência do setor de serviços por conta de seus menores níveis de produtividade e dinâmica mais lenta em relação à indústria de transformação. No entanto, essa visão tradicional dos serviços como desvios de produtividade e absorventes de emprego tem sido questionada pelo grande dinamismo que alguns segmentos de serviços avançados mostram em relação ao surgimento e difusão de TICs (CASTELLACCI, 2007).

Recentemente, um novo conjunto de inovações radicais inter-relacionadas tem sido progressivamente introduzido no sistema econômico; primeiro na indústria de semicondutores e, mais tarde, nos setores de software e de telecomunicações. Começam a se difundir mais rapidamente a partir do início dos anos 1990. Como parte da difusão das novas tecnologias, um conjunto relacionado de inovações se espalhou, baseado na multimídia e na Internet, ligado às atividades de publicação e entretenimento, e a toda uma gama de novos serviços (redes de voz, cabo, celular e comunicações por satélite, transmissão de dados,

7 Os dados para a Alemanha não estão disponíveis nesta mesma metodologia. 
redes, etc.). O crescimento dos serviços avançados está, portanto, relacionado ao surgimento de um novo paradigma tecnológico caracterizado pela penetração e o potencial de crescimento trazido pelas TICs (CASTELLACCI, 2007; FREEMAN; LOUÇÃ, 2001).

O avanço observado nestes serviços define um padrão de terceirização que pode ser explicada pelas diferentes atribuições das atividades existentes, e não por um processo real de mudança e criação estrutural de serviços inteiramente novos, e que está inerentemente relacionada à crescente complexidade do processo produtivo baseado no conhecimento. Portanto, constitui um aspecto importante da maior especialização tecnológica e econômica que caracteriza a produção moderna (FIXLER; SIEGEL, 1999).

Assim, a terceirização reflete um intenso processo de mudança estrutural e uma reorganização radical da divisão do trabalho entre setores tecnologicamente avançados. Logo, esse processo está levando a uma interdependência crescente entre ambos os setores (indústria e serviços intensivos em conhecimento) e a um intercâmbio de conhecimento mais intenso entre atividades da indústria e serviços. Um fator crucial de vantagem competitiva no novo paradigma tecnológico baseado em TICs é representado pela interdependência e vínculos verticais que unem diferentes grupos de setores de manufatura e serviços (ANTONELLI, 1998; DI CAGNO; GUERRIERI; MELICIANI, 2005; MELICIANI, 2005; WINDRUM; TOMLINSON, 1999;).

Neste contexto, comprova-se que a produtividade do trabalho das indústrias relacionadas às novas tecnologias de propósitos gerais, principalmente aquelas relacionadas às TICs, aumentou progressivamente sua contribuição para o crescimento da economia, enquanto a relacionada ao núcleo industrial fordista apresentou uma tendência à estagnação ou decréscimo (CASTELLACCI, 2007).

Frente à produtividade, os grupos tecnologicamente mais avançados vêm aumentando significativamente sua contribuição para a produtividade agregada do trabalho desde o início dos anos 1980. Seu nível de produtividade está muito acima da média da economia. Já os últimos (grupos tecnicamente menos dinâmicos) são caracterizados por tendências estáveis ou decrescentes da produtividade (CASTELLACCI, 2007).

Gráfico 03 - Produtividade do Trabalho dos Estados Unidos, Brasil e Alemanha (US\$ de 2016, PPP de 2011) - 1960 a 2016

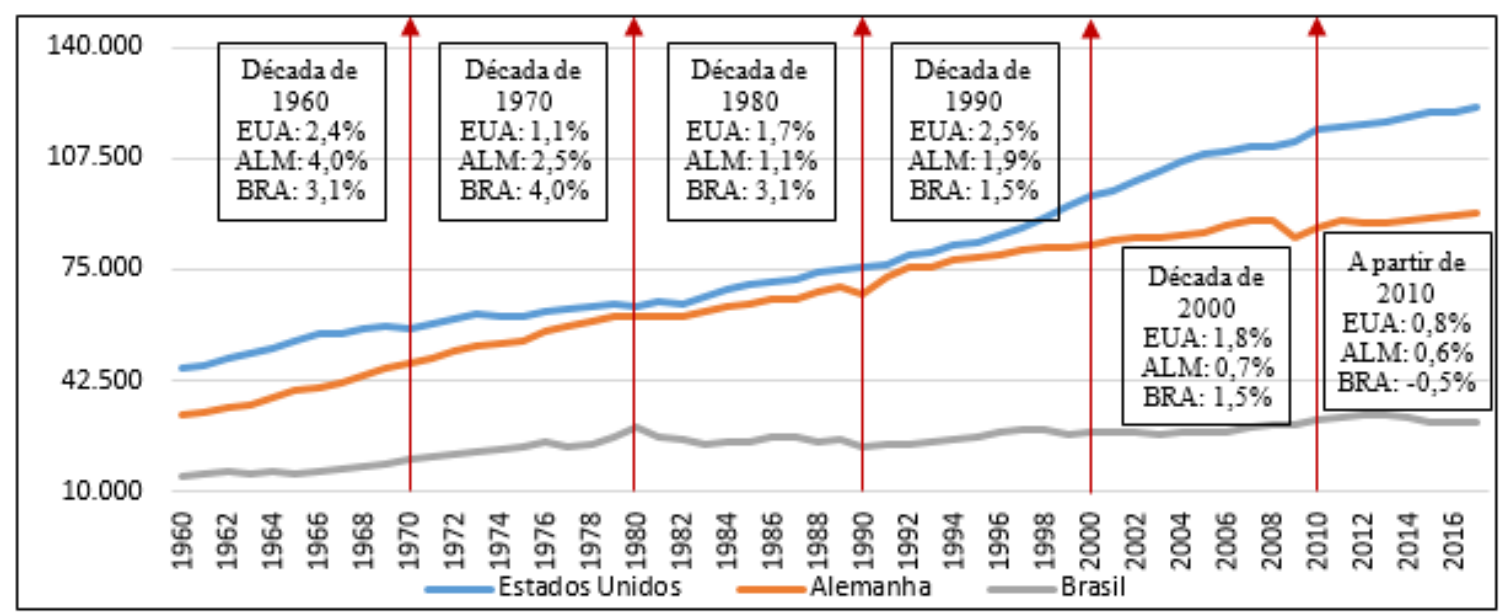

Fonte: The Conference Board (2017).

A partir do Gráfico 03, verifica-se como evoluiu a produtividade do trabalho nos Estados Unidos (EUA), na Alemanha (ALM) e no Brasil (BRA). A escolha dos países deu-se em razão de ilustrarem o apresentado até então. Assim, os Estados Unidos figuram como país de destaque no que se refere às TICs, comparado à realidade europeia - representada pela Alemanha -, e o Brasil é apresentado como país central de análise. Destaca-se, primeiramente, que a produtividade brasileira apresentou, nas décadas de 1960 e 1970, a maior variação média. Nestas décadas, o país passava por um processo de industrialização pesada. Em seguida, a forma como a produtividade norte-americana eleva-se na década de 1990, ratificando o efeito explanado acerca das TICs. Ainda no que tange a este tema, aponta-se a redução das taxas de crescimento da produtividade brasileira, principalmente da década de 1990 até a atual, o que evidencia que o efeito observado nos Estados Unidos e, em menor proporção, na Alemanha, não ocorreu no Brasil. 
O setor de TICs imprimiu amplo efeito na produtividade agregada através de seu papel de promotor de inovações complementares, incluindo a reorganização de negócios em outros serviços. O crescimento médio da produtividade de bens e serviços relacionados às TICs liderou todos os setores durante o período 2000-2007, particularmente nos Estados Unidos e nos países nórdicos. Em contrapartida, o Japão, a Europa central e os países da área do euro com alto endividamento demoraram a se modernizar neste quesito (DABLA-NORRIS et al., 2015).

Em síntese, o cenário mundial acerca da produtividade é de estagnação. Por vezes, atribui-se este comportamento aos processos de desindustrialização, o que promove redução da indústria - setor de alta produtividade - em benefício do aumento da participação do setor de serviços - setor de produtividade inferior - nas economias. Porém, verifica-se que este processo coloca-se dúbio, ele depende da conformação da estrutura produtiva previamente ao seu acontecimento.

Nas desenvolvidas avançadas, a terceirização de atividades da indústria para o setor de serviços decorre do aprofundamento do paradigma tecnológico fundamentado nas TICs. Este se inicia após a consolidação de um setor industrial robusto. Nas economias em desenvolvimento, observa-se que o processo de desindustrialização inicia-se antes de se alcançar a consolidação do setor industrial, o que dá origem a um setor de serviços desintegrado aos demais setores produtivos.

\section{Mudança estrutural e a produtividade: o caso do Brasil}

Frente à lógica atual de mudança estrutural observada nas economias desenvolvidas, a realidade setorial brasileira é analisada na presente seção visando identificar o que explica a estagnação da produtividade brasileira. No Gráfico 04, observa-se a evolução da produtividade brasileira de 1950 a 2011. No eixo primário, apresentam-se os setores da economia exceto a mineração e a produtividade total em milhões de dólares por trabalhador (valores de 2005). No eixo secundário, a mineração. A escolha por colocar a mineração em um eixo secundário decorre da elevação recente da produtividade deste setor, que ofusca a análise dos demais setores.

Gráfico 04 - Produtividade total e setorial brasileira (milhões de US\$ de 2005 por pessoal ocupado) - 1950 a 2011

Fonte: GGDC (2017).

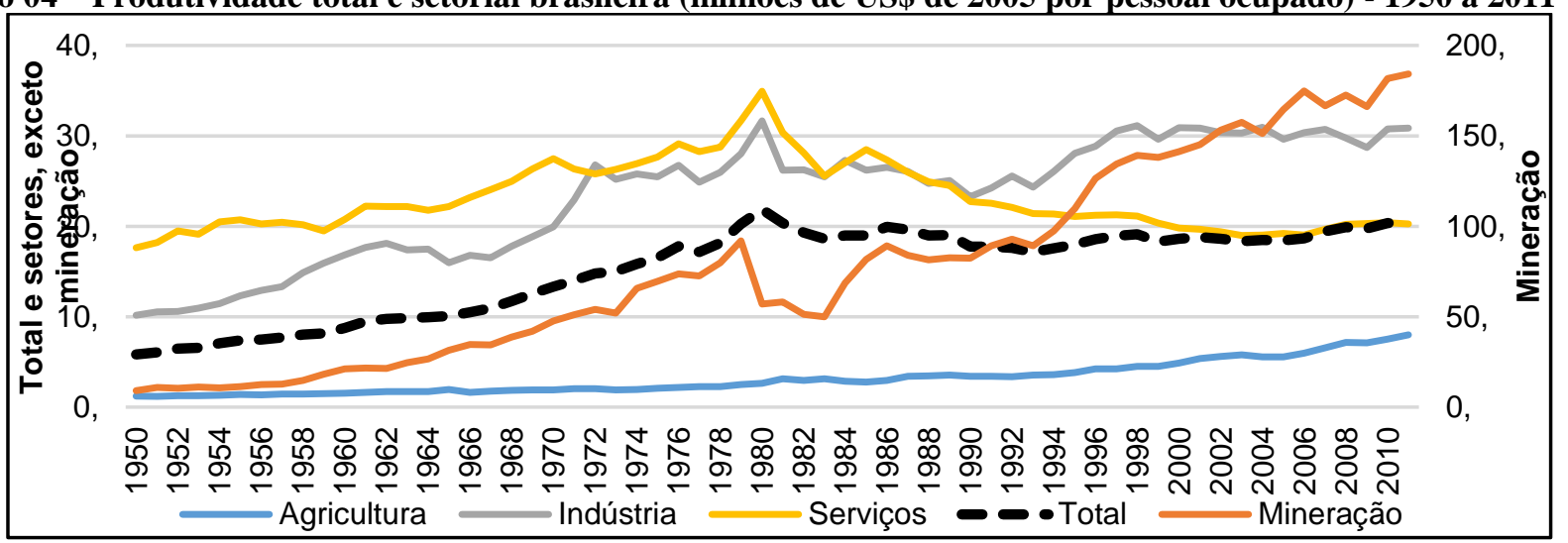

Segundo Dabla-norris et al. (2015), a alteração na produtividade dos países latino-americanos decorre da realocação setorial, mudança estrutural, em direção a setores de menor produtividade. A produtividade total se eleva até o início da década de 1980, em correspondência ao aumento da produtividade da indústria e do setor de serviços. No início da série, o setor de serviços apresenta produtividade superior àquela observada na indústria. Posteriormente, a produtividade da indústria mantém o movimento de elevação, e a produtividade do setor de serviços declina. Assim, dois movimentos contribuem para a estagnação da produtividade brasileira nos anos recentes: a redução da participação da indústria no PIB e a redução da produtividade do setor de serviços. A recente elevação da produtividade da indústria é motivada, em grande parte, pelo aumento da produtividade da indústria extrativa (mineração). 


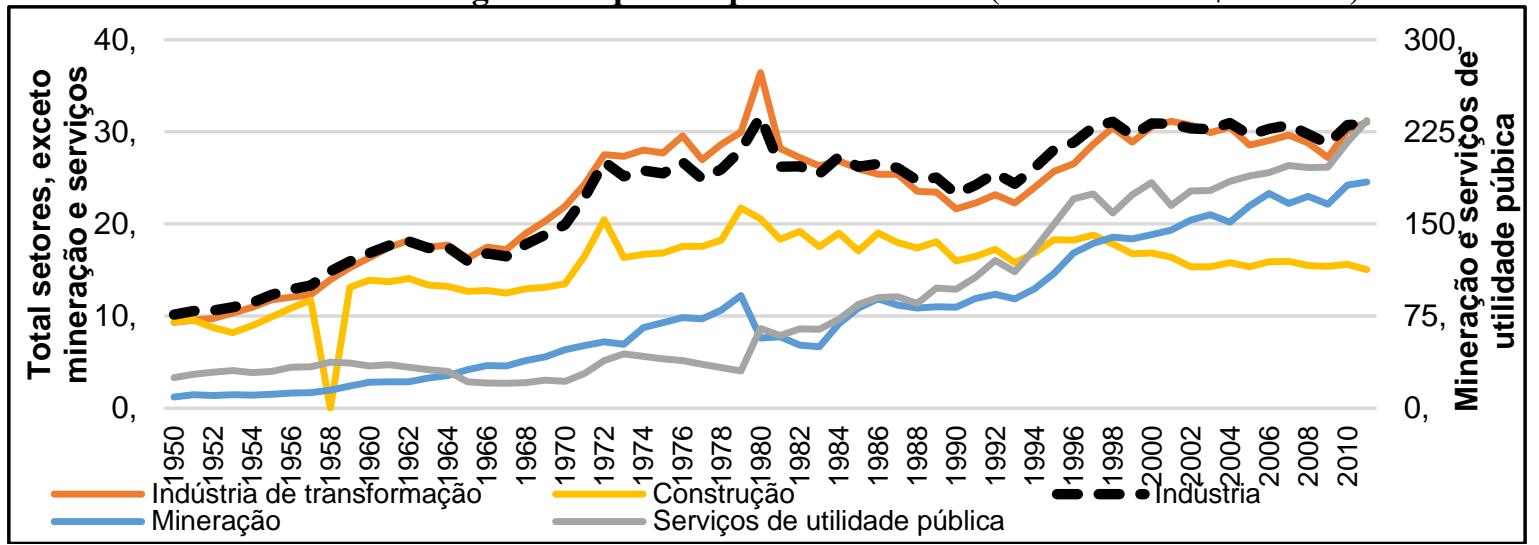

Fonte: GGDC (2017).

A produtividade dos segmentos que compõem a indústria é apresentada no Gráfico 05 . O comportamento da indústria extrativa (mineração) e dos serviços industriais de utilidade pública vêm representados no eixo secundário, pois ofuscam os movimentos dos demais setores. Porém, estes setores pouco condicionam a produtividade da indústria como um todo, o que decorre de suas baixas participações tanto no valor adicionado quanto no emprego (Tabela 1). O segmento de maior expressividade na produtividade total da indústria é o de transformação, o que é explicado pelo peso que este tem para o setor industrial. Dada a elevada participação do segmento de transformação no setor industrial - muito superior à dos demais -; quando se aponta a redução da participação da indústria no PIB, esta afirmação refere-se, principalmente, à indústria de transformação.

Tabela 1 - Participação dos segmentos da indústria no total do emprego e valor adicionado do setor industrial - décadas de 1950, 1960, 1970 e 2000 (até 2011)

Segmento Participacão na indústria $(\%)$

\begin{tabular}{lcccccc}
\hline & \multicolumn{5}{c}{ Valor adicionado } \\
& \multicolumn{5}{c}{ Décadas } \\
\cline { 2 - 7 } & $\mathbf{1 9 5 0}$ & $\mathbf{1 9 6 0}$ & $\mathbf{1 9 7 0}$ & $\mathbf{1 9 8 0}$ & $\mathbf{1 9 9 0}$ & $\mathbf{2 0 0 0}$ \\
\cline { 2 - 7 } Mineração & 2,7 & 4,0 & 4,1 & 5,8 & 7,2 & 8,3 \\
Indústria de transformação & 65,7 & 68,4 & 66,9 & 62,0 & 59,2 & 60,5 \\
Serviços de utilidade pública & 13,1 & 8,2 & 7,1 & 9,4 & 13,3 & 13,3 \\
Construção & 18,4 & 19,4 & 21,9 & 22,8 & 20,3 & 17,9 \\
Indústria & 100,0 & 100,0 & 100,0 & 100,0 & 100,0 & 100,0 \\
& & & Emprego & & 1,0 \\
Mineração & 2,8 & 2,3 & 1,6 & 2,2 & 1,8 & 1,5 \\
Indústria de transformação & 70,1 & 66,6 & 61,9 & 62,0 & 63,6 & 61,8 \\
Serviços de utilidade pública & 5,2 & 5,5 & 5,2 & 3,2 & 2,6 & 2,1 \\
Construção & 22,0 & 25,6 & 31,3 & 32,7 & 31,9 & 34,6 \\
Indústria & 100,0 & 100,0 & 100,0 & 100,0 & 100,0 & 100,0 \\
\hline GGDC (2017) & & & & & \\
\hline
\end{tabular}

Fonte: GGDC (2017).

Nota: Dados numéricos arredondados.

A produtividade do setor de serviços, conforme observa-se no Gráfico 06, cresce até 1980. A produtividade do setor de serviços é bastante condicionada pelo segmento de comércio, restaurante e hotéis. Este comportamento é reflexo da expressiva participação do segmento citado no setor, principalmente no 
que se refere ao emprego, que alcança índices superiores a 30\% em toda a série analisada. Por outro lado, a participação dos demais segmentos mostra-se bastante pulverizada, conforme observa-se na Tabela 02.

No tocante ao Valor Adicionado, Comércio, restaurantes e hotéis, Serviços financeiros, seguros, imobiliário e comercial e Serviços governamentais representam os segmentos de maior representatividade. Deste, o primeiro reduz sua participação ao longo dos anos, enquanto o último apresenta aumento. Referente ao emprego, o segmento Comércio, restaurantes e hotéis é aquele de maior participação na série, com, aproximadamente, mais de 10 pontos percentuais em relação ao segundo segmento, Serviços comunitários, sociais e pessoais.

Gráfico 06 - Produtividade dos segmentos que compõem o setor de serviços (milhões de US\$ de 2005) - 1950 a 2011

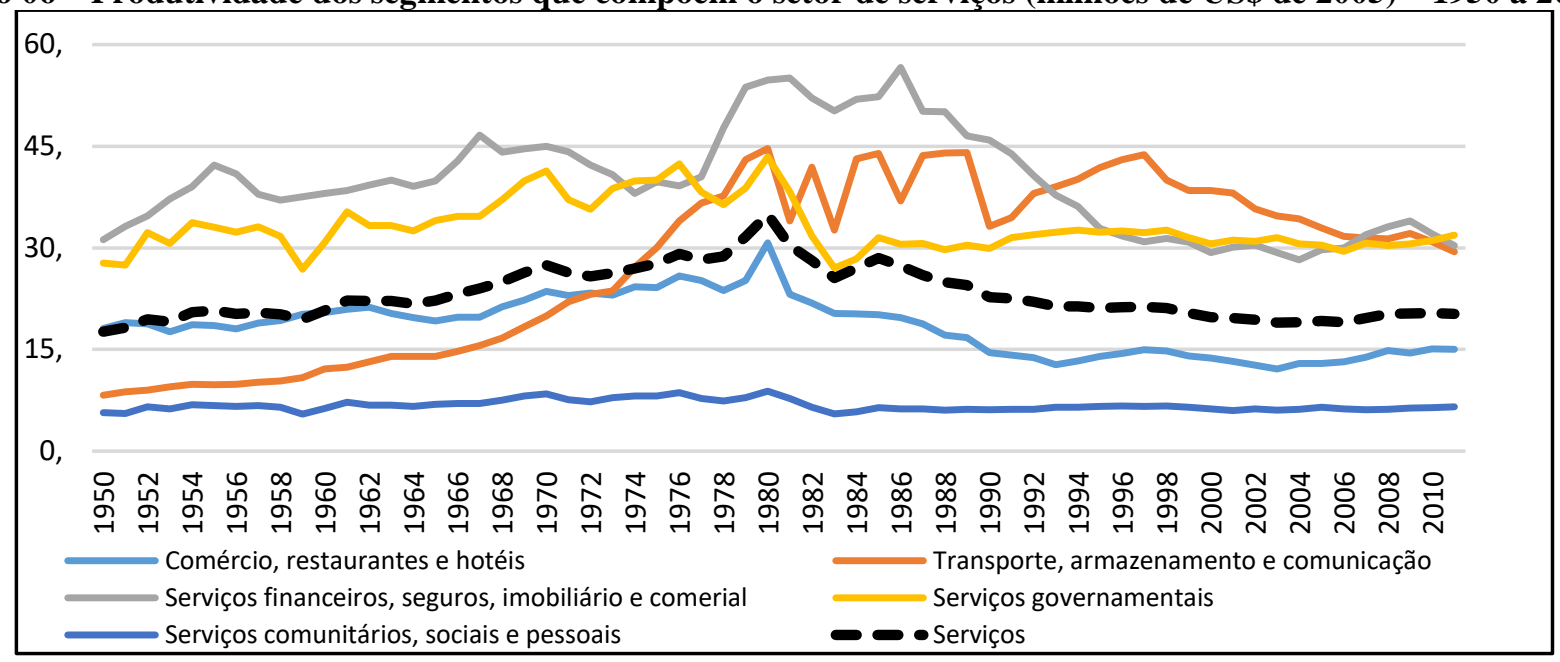

Fonte: GGDC (2017).

Tabela 2 - Participação dos segmentos de serviços no total do emprego e valor adicionado do setor industrial - décadas de 1950, 1960, 1970 e 2000 (até 2011)

\begin{tabular}{l|cccccc}
\hline \multicolumn{1}{c}{ Segmento } & \multicolumn{5}{c}{ Participação no setor de serviços (\%) } \\
\hline & \multicolumn{5}{c}{ Valor adicionado } \\
& \multicolumn{5}{c}{ Décadas } \\
\cline { 2 - 8 } & $\mathbf{1 9 5 0}$ & $\mathbf{1 9 6 0}$ & $\mathbf{1 9 7 0}$ & $\mathbf{1 9 8 0}$ & $\mathbf{1 9 9 0}$ & $\mathbf{2 0 0 0}$ \\
\cline { 2 - 8 } Comércio, restaurantes e hotéis & 32,6 & 28,9 & 26,5 & 22,5 & 22,0 & 23,5 \\
Transporte, armazenamento e comunicação & 7,4 & 7,8 & 8,9 & 10,2 & 13,3 & 12,7 \\
Serviços financeiros, seguros, imobiliário e comercial & 24,0 & 27,5 & 30,1 & 37,3 & 27,1 & 25,5 \\
Serviços governamentais & 29,9 & 29,7 & 28,7 & 24,8 & 30,9 & 31,1 \\
Serviços comunitários, sociais e pessoais & 6,1 & 6,1 & 5,9 & 5,1 & 6,7 & 7,2 \\
Serviços & 100,0 & 100,0 & 100,0 & 100,0 & 100,0 & 100,0 \\
\hline
\end{tabular}

Comércio, restaurantes e hotéis

Emprego

Transporte, armazenamento e comunicação

\begin{tabular}{lcccccc} 
& 34,2 & 32,7 & 30,7 & 30,5 & 33,5 & 33,6 \\
& 15,0 & 12,5 & 8,2 & 6,9 & 7,3 & 7,6 \\
& 12,6 & 15,2 & 19,4 & 19,7 & 16,2 & 16,3 \\
& 19,0 & 19,8 & 20,8 & 21,4 & 20,7 & 19,9 \\
& 19,1 & 19,9 & 20,9 & 21,5 & 22,3 & 22,6 \\
& 100,0 & 100,0 & 100,0 & 100,0 & 100,0 & 100,0 \\
\hline
\end{tabular}

Serviços financeiros, seguros, imobiliário e comercial

Serviços governamentais

Serviços comunitários, sociais e pessoais

100

Serviços

Fonte: GGDC (2017).

Nota: Dados numéricos arredondados. 
O setor de TICs ainda tem muito a se desenvolver, na realidade brasileira, tanto em seus elementos mais fundamentais quanto no relacionamento que estabelece com os demais setores. Não obstante, seu impacto no crescimento do emprego é notório. Segundo a Pesquisa Anual de Serviços (PAS), em 2002 (dado mais antigo disponível), a participação do setor de Tecnologia da Informação (TI) no total de empregos do setor de serviços foi de 3,2\%. Em 2014, tal participação subiu para 4,5\%. O problema é que a participação no valor adicionado apresentou variação muito menor: de 6,6\% em 2002 para 6,9\% em 2014. Assim, pode-se concluir que a produtividade do setor de TI é superior àquela observada no setor de serviços, porém apresenta redução relativa de 2002 para 2014. Pode-se então questionar a capacidade do setor de promover a produtividade dos demais, uma vez que ele próprio apresenta dificuldade em sustentar sua produtividade ao longo do período (IBGE, 2017).

Assim, diante do comportamento da produtividade brasileira, podemos apontar dois aspectos preponderantes: a redução da participação da indústria de transformação no PIB - pois este setor apresenta segunda maior produtividade setorial recente e representatividade em termos de participação no emprego; e redução na produtividade do setor de serviços, juntamente com o aumento de sua participação no emprego total da economia nacional.

Nos períodos de avanço da indústria, a economia brasileira passou por um intenso movimento de êxodo rural. Os trabalhadores que deixaram a agricultura deslocaram-se para as cidades e inseriram-se principalmente na indústria. Atualmente, é possível observar que tanto os trabalhadores provenientes da agricultura quanto os do setor industrial inserem-se no setor de serviços, pois, neste último, não há necessidade de ampla qualificação como nos demais. A inserção maciça de trabalhadores no setor de serviços promove redução da produtividade, pois não se observa contrapartida igual no valor adicionado setorial.

Tratando-se da participação setorial do emprego, a agricultura detinha, na década de 1950, participação média de $62 \%$ no emprego brasileiro. Este valor se reduz aos poucos, até alcançar $16 \%$ em 2010. Concomitante a este movimento, o emprego do setor de serviços eleva-se em proporção semelhante. Na década de 1950, a participação do setor de serviços na economia era de 21,5\%; ao passo que, em 2010, elevou-se para $61 \%$.

No que se refere a estes movimentos, Timmer, De Vries e De Vries (2014) apresentam o resultado da aplicação de um método de decomposição canônica visando aprofundar a análise da mudança da produtividade agregada. Este método permite compreender os efeitos da realocação do emprego na produtividade, evidenciando se a variação da produtividade decorreu da variação da produtividade setorial, do deslocamento do emprego para setores de níveis distintos de produtividade ou onde observa-se variação na mesma. Os movimentos descritos estão sintetizados em três efeitos, apresentados no Quadro 01:

Quadro 1 - Descrição efeitos - decomposição canônica da produtividade
\begin{tabular}{|l|l|l|}
\hline Efeitos & \multicolumn{1}{|c|}{ Causa } & \multicolumn{1}{c|}{ Interpretação } \\
\hline Within-effect & Mudanças de produtividade setorial. & É positivo quando a produtividade setorial aumenta. \\
\hline $\begin{array}{l}\text { Realocação } \\
\text { estático }\end{array}$ & $\begin{array}{l}\text { Deslocamento do emprego entre setores de } \\
\text { produtividade distinta. }\end{array}$ & $\begin{array}{l}\text { É positivo quando o emprego se desloca para setores } \\
\text { de produtividade maior que a média. }\end{array}$ \\
\hline $\begin{array}{l}\text { Realocação } \\
\text { dinâmico }\end{array}$ & $\begin{array}{l}\text { Deslocamento do emprego entre setores com } \\
\text { taxa de crescimento da produtividade distintas. }\end{array}$ & $\begin{array}{l}\text { É positivo quando o emprego se desloca para setores } \\
\text { onde a produtividade é crescente. }\end{array}$ \\
\hline
\end{tabular}

Fonte: Elaboração própria com base em Timmer, De Vries e De Vries (2014).

O método pode ser expresso pela Equação (1):

$$
\Delta P=\sum_{i}\left(P_{i}^{T}-P_{i}^{0}\right) S_{i}^{0}+\sum_{i}\left(S_{i}^{T}-S_{i}^{0}\right) P_{i}^{0}+\sum_{i}\left(P_{i}^{T}-P_{i}^{0}\right) x\left(S_{i}^{T}-S_{i}^{0}\right)
$$

O termo $S_{i}$ representa a participação do setor $i$ no emprego total da economia; $P_{i}$, o nível de produtividade do trabalho do setor $i$; o sobrescrito 0 refere-se ao período inicial, e o subscrito $\mathrm{T}$ ao final. $\mathrm{O}$ primeiro somatório diz respeito ao "within-effect"; o segundo, ao efeito de realocação estático; e o terceiro, ao efeito de realocação dinâmico. 
É importante ressaltar que esta metodologia permite compreender os efeitos da realocação setorial do emprego na produtividade e que tal fator importa uma vez que se pretende compreender as características do processo observado de crescimento da participação do setor de serviços na economia. Do resultado obtido, pode-se sugerir e avalizar com o aporte de dados adicionais a natureza do processo descrito.

Os três efeitos são observados em três períodos distintos: 1960-1975 (boom econômico mundial), 1975-1990 (mudança radical nos prospectos econômicos para as economias em desenvolvimento) e 19902010 (retomada do crescimento). Estes períodos são utilizados em vários estudos econômicos. Os resultados dos três efeitos para o Brasil são apresentados na Tabela 3:

Tabela 3 - Decomposição da produtividade do Brasil - 1960-1975, 1975 -1990 e 1990 -2010

\begin{tabular}{cccc}
\hline \multirow{2}{*}{ Período } & \multicolumn{3}{c}{ Efeito } \\
\cline { 2 - 4 } & Within-effect & Realocação estático & Realocação dinâmico \\
\hline $1960-1975$ & $1,9 \%$ & $2,0 \%$ & $0,3 \%$ \\
$1975-1990$ & $-0,5 \%$ & $1,4 \%$ & $-0,5 \%$ \\
$1990-2010$ & $0,7 \%$ & $0,4 \%$ & $-0,4 \%$ \\
\hline
\end{tabular}

Fonte: Elaboração e cálculo próprios com base em dados coletados em GGDC (2017).

Nota: Dados numéricos arredondados.

Assim, para a realidade brasileira, no primeiro período, os três efeitos da decomposição foram positivos, sendo os efeitos de realocação estático e o "within-effect" maiores que o efeito de realocação dinâmico. Isto significa que houve aumento da produtividade dentro dos setores, aumento da participação no emprego por parte de setores mais produtivos (efeitos mais sobressalentes) e também expansão do emprego em setores cuja produtividade cresce. De 1960 a 1975, a agricultura reduziu em 17\% sua participação no emprego brasileiro. Em compensação, a participação da indústria aumentou em 5\%; e o setor de serviços, em $12 \%$. Os setores cuja participação cresceu apresentavam produtividade superior à da agricultura, muito embora, neste período, a produtividade de todos os setores da economia tenha crescido.

No segundo período, apenas o efeito realocação estático é positivo. Ou seja, houve aumento da participação no emprego de setores mais produtivos; porém, a produtividade setorial declinou. $\mathrm{O}$ efeito de realocação dinâmica negativo aponta que os trabalhadores moveram-se para setores que apresentaram retração de produtividade. Pode-se observar que, de 1975 a 1990, a agricultura seguiu perdendo participação no emprego nacional (-15\%); por usa vez, a indústria elevou sua participação em 1,4\%, e o setor de serviços mostrou-se o grande absorvedor de empregos, elevando sua participação em $14 \%$. O segundo efeito é positivo, pois a produtividade dos setores de indústria e de serviços - que absorvem emprego - foi maior do que a da agricultura. Contudo, a produtividade decaiu de 1975 para 1990 na indústria $(-21,8 \%)$ e nos serviços $(-17,8 \%)$.

$\mathrm{O}$ "within-effect" e o efeito de realocação estático são positivos e mais baixos no terceiro período; o que significa aumento da produtividade setorial e deslocamento de emprego para setores de produtividade superior à media. Todavia, o efeito de realocação dinâmico é negativo, o que implica que o emprego se expandiu em setores em que a produtividade decaiu. A produtividade brasileira aumentou 14,5\% nos 20 anos compreendidos entre 1990 e 2010. Apenas o setor de serviços ganhou participação no emprego $(12,2 \%)$. A indústria de transformação reduziu aproximadamente 3\% e a agricultura contraiu 10\%. Destes setores, a produtividade elevou-se na agricultura e na indústria de transformação, reduzindo-se justamente no setor de serviços, no qual a participação no emprego se elevou.

Neste contexto, conclui-se que, para o caso brasileiro, a evolução da produtividade é coerente com a mudança estrutural observada. No primeiro período, tanto o crescimento da indústria quanto do setor de serviços no emprego traz consigo aumento de produtividade, uma vez que estes setores mostram-se mais produtivos que a agricultura. Pode-se afirmar que, a partir do segundo período, o comportamento da produtividade é coerente com o aumento do emprego em setores onde a produtividade decresce, principalmente no setor de serviços o que evidencia que a terceirização capaz de aumentar a complexidade econômica, conforme apresentado na seção anterior, não ocorre no caso brasileiro. 
Em realidade, neste caso, o crescimento da participação do setor de serviços no emprego relacionase mais com um aumento do emprego nos segmentos de Serviços financeiros, seguros, imobiliário e comercial e Serviços comunitários, sociais e pessoais, do que da terceirização nos moldes explanados. Segundo Arbache (2015, p. 277), o crescimento do setor de serviços não decorreu do aumento da renda média, de mudança da composição da demanda, do crescimento industrial "ou outros fatores que poderiam ter desencadeado o desenvolvimento do setor de serviços, como acontecera nos países industrializados". Ou seja, não ocorreu no Brasil a terceirização inteligente fomentada a partir de um processo completo de industrialização.

Ainda como descreve Arbache (2015, p. 277), a participação do setor de serviços cresce mais em razão do crescimento vegetativo e perda de dinamismo de outros setores do que do que ocorre no próprio setor de serviços. O crescimento da população urbana e a transformação demográfica podem ter contribuído para isso assim como as características do próprio setor de serviços - baixo custo à entrada, baixa necessidade de capital humano, tecnológico. Assim, o setor de serviços foi "a melhor, senão a única oportunidade de renda e emprego para boa parte do contingente de pessoas que chegava ao mercado de trabalho".

\section{Síntese conclusiva}

Atualmente, o cenário mundial acerca da produtividade é de estagnação. Por vezes, atribui-se este comportamento aos processos de desindustrialização, o que promove redução da indústria - setor de alta produtividade - em benefício do aumento da participação do setor de serviços - setor de produtividade inferior - nas economias. Porém, verifica-se que este processo coloca-se dúbio, uma vez que ele depende da conformação da estrutura produtiva previamente ao seu acontecimento.

Nas economias avançadas, a terceirização de atividades da indústria para o setor de serviços decorre do aprofundamento do paradigma tecnológico fundamentado nas TICs. Este se inicia após a consolidação de um setor industrial robusto. Nas economias em desenvolvimento, observa-se que o processo de desindustrialização inicia-se antes de se alcançar a consolidação do setor industrial, o que dá origem a um setor de serviços pouco integrado aos demais setores produtivos.

Neste contexto, conclui-se que, para o caso brasileiro, a evolução da produtividade é coerente com a mudança estrutural observada. No primeiro período, tanto o crescimento da indústria quanto do setor de serviços no emprego traz consigo aumento de produtividade, uma vez que estes setores mostram-se mais produtivos que a agricultura. Pode-se afirmar que, a partir do segundo período, o comportamento da produtividade é coerente com o aumento do emprego em setores onde a produtividade decresce, principalmente no setor de serviços, o que evidencia que a terceirização capaz de aumentar a complexidade econômica não ocorre no caso brasileiro.

No caso brasileiro, o crescimento da participação do setor de serviços no emprego relaciona-se mais com um aumento do emprego nos segmentos de Serviços financeiros, seguros, imobiliário e comercial e Serviços comunitários, sociais e pessoais, do que da terceirização nos moldes explanados. O setor de serviços cresceu mais devido à ausência de dinamismo nos outros setores do que por conta do próprio dinamismo. Suas características de baixo custo à entrada o transformaram na opção mais viável de emprego àqueles que adentravam ao mercado de trabalho.

\section{Referências bibliográficas}

ANTONELLI, C. Localized technological change, new information technology and the knowledge-based economy: the European evidence. Journal of Evolutionary Economics, v. 8, n. 2, p. 177-198, jul. 1998.

ARBACHE, J. Produtividade no setor de serviços. In: NEGRI, Fernanda de; CAVALCANTE, L. R. (Orgs.). Produtividade no Brasil: desempenho e determinantes. Brasília: Njobs Comunicação, 2015. v. 2, p. 277-300. 
Baumol, W. J. (1967), 'Macroeconomics of unbalanced growth: the anatomy of urban crisis', The American Economic Review 57(3), 415-426.

Baumol, W. J., Blackman, S. A. B. \& Wolff, E. N. (1985), 'Unbalanced growth revisited: asymptotic stagnancy and new evidence', The American Economic Review 75(4), 806-817.

Busso, M., Madrigal, L. \& Pages, C. (2013), 'Productivity and research missallocation in latin american', The B.E. Journal of Macroeconomics 13(1), 903- 932.

BIELSCHOWSKY, R. Cinquenta anos de pensamentos na CEPAL: Uma resenha. In: Cinquenta anos de pensamento na CEPAL. Rio de Janeiro: Record, 2000. p. 13-68.

CASTELLACCI, F. Technological paradigms, regimes and trajectories: Manufacturing and service industries in a new taxonomy of sectoral patterns of innovation. Research Policy, Oslo, v. 1, n. 37, p. 978-994, 15 maio 2008. Disponível em: <https://myweb.rollins.edu/tlairson/pek/techpara2.pdf>. Acesso em: 12 set. 2017.

DABLA-NORRIS, Era et al. The New Normal: A Sector-Level Perspective on Productivity Trends in Advanced Economies. Washington: Fmi, 2015. 38 p.

DI CAGNO, D., MELICIANI, V. Do inter-sectoral flows of services matter for productivity growth? An input/output analysis of OECD countries. Economics of Innovation and New Technology, v. 14, n. 3: 149-171, 2005.

DOSI S. et. al. (Eds). Technical Change and Economic Theory. London: Pinter, 1988.

FABRICANT, S. Employment in Manufacturing, 1899-1939. NBER, New York, 1942.

FAJNZYLBER, F. La industrialización trunca de América Latina. Cidade do México: Editorial Nueva Imagen, 1983.

FIXLER, D.; SIEGAL, D. Outsourcing and productivity growth in services. Structural Change and Economic Dynamics, n. 10, p. 177-194, 1999.

FREEMAN, C. 1974. The Economics of Industrial Innovation. 2. ed. London: Frances Pinter, 1982.

FREEMAN, C., LOUÇÃ, F. As Time Goes by: From the Industrial Revolutions to the Information Revolution. Oxford: Oxford University Press, 2001.

FURTADO, C. Desenvolvimento e Subdesenvolvimento. Rio de Janeiro: Fundo de Cultura, 1961.

GUERRIERI, P., MELICIANI, V. Technology and international competitiveness: the interdependence between manufacturing and producer services. Structural Change and Economic Dynamics, n. 16, p. 489-502, 2005.

Jacinto, P. d. A., \& Ribeiro, E.P. (2015). Crescimento da produtividade no setor de serviços e da indústria no Brasil: Dinâmica e heterogeneidade. Economia Aplicada, 19(3), 401-427. 
MACEDO, B. G. Desenvolvimento Econômico: A atualidade da economia política cepalina. 2007. 217 f. Tese (Doutorado em Economia) - Universidade Estadual de Camppinas, Campinas, 2007.

MARCONI, Nelson; ARAGÃO, Roberto Barbosa de Andrade. Demand and supply factors on the explanation of structural change. Porto: Fmm, 2016.

MALERBA, F.; ORSENIGO, L. Technological Regimes and Sectoral Patterns of Innovative Activities. Oxford Jornals, v. 6, n. 1, p. 83-118, 2006.

Melo, H. P., Rocha, F., Ferraz, G., Di Sabbato, A. \& Dweck, R. (1998), 'O setor serviços no Brasil: uma visão global - 1985/95'.

MCMILLAN, Margaret, and RODRIK, Dani, "Globalization, Structural Change, and Economic Growth," in M. Bachetta and M. Jansen, eds., Making Globalization Socially Sustainable, International Labor Organization and World Trade Organization, Geneva, 2011.

NELSON, R. R.; WINTER, S. G. An evolutionary theory of economic change. Cambridge, Massachusetts, EUA: Harvard University Press, 1982.

Rodrik, Dani, "Unconditional Convergence in Manufacturing," Quarterly Journal of Economics, 128 (1), February 2013, 165-204.

Rodrik, D. (2011), 'O imperativo manufatureiro', Valor econômico.

Rodrik, D. (2014), ‘Are services the new manufactures?', Valor econômico

RODRIGUEZ, O. O Estruturalismo Latino-Americano. Rio de Janeiro: Record, 2006.

Silva, A. M. (2006), Dinâmica da produtividade do setor de serviços no Brasil: uma abordagem microeconômica, in J. A. Negri \& L. C. Kubota, eds, 'Estrutura e Dinâmica do Setor de Serviços no Brasil', Vol. 1, IPEA

Oliveira, C. C. (2011), 'Os serviços importam: análise comparativa da evolução setorial da produtividade do trabalho no Brasil, nos EUA e na EU-15 (1980-2007): uma aplicação do modelo Shift share', XXXIX Encontro Nacional de Economia, Foz do Iguaçú, Paraná.

Pereira, M. Z., Bastos, S. Q. A. \& Perobelli, F. S. (2013), 'Análise sistêmica do setor de serviços no Brasil para o ano de 2005', Pesquisa e Planejamento Econômico 43(1), 161-201.

THE CONFERENCE BOARD (Estados Unidos). Productivity data. 2015. Disponível em: . Acesso em: 06 ago. 2016.

THE CONFERENCE BOARD. Productivity Brief 2015: Global Productivity Growth Stuck in the Slow Lane with No Signs of Recovery in Sight. Nova York, 2015. 26 p. Disponível em:

<https://www.conference-board.org/retrievefile.cfm?filename=the-conference-board-2015-productivitybrief.pdf\&type=subsite $>$. Acesso em: 12 set. 2017.

TIMMER, Marcel P.; VRIES, Gaaitzen DE VRIES And Klaas de. Patterns of Structural Change in Developing Countries. Groningen: Groningen Growth And Development Centre, 2014. 31 p. 
Timmer, Marcel P. \& Szirmai, Adam, 2000. "Productivity growth in Asian manufacturing: the structural bonus hypothesis examined," Structural Change and Economic Dynamics, Elsevier, vol. 11(4), pages 371-392, December.

WINDRUM, P., TOMLINSON, M. Knowledge-intensive services and international competitiveness: a four country comparison. Technology Analysis and Strategic Management, v. 11, n. 3, p. 391-408, 1999. 